\title{
Pelatihan Membuat Daftar Pustaka Otomatis Dengan Aplikasi Mendeley Desktop Bagi Mahasiswa Dalam Persiapan Penyusunan Tugas Akhir
}

\author{
Fani Juliyanto Perdana \\ Sekolah Tinggi Ilmu Kesehatan Cirebon \\ e-mail: fanijuliyanto@gmail.com
}

\begin{abstract}
ABSTRAK
Dalam penulisan karya ilmiah, baik skripsi, thesis, maupun disertasi. Mencantumkan daftar pustaka adalah hal yang wajib dilakukan untuk menghindari plagiarism. Dalam melakukan penulisan tugas akhir mahasiswa tidak lepas dari yang namanya referensi. Akan banyak referensi yang akan kita sisipkan dalam membuat karya tulis tersebut. Sudah pasti akan menyulitkan kita jika membuat daftar pustakanya secara manual. Daftar pustaka sebisa mungkin dicantumkan secara lengkap serta seragam, sesuai dengan pola atau gaya yang dianjurkan oleh standar penulisan karya ilmiah pada kampus tersebut. Untuk mempermudah dalam membuat daftar pustaka secara otomatis, saat ini telah ada aplikasi yang dapat kita gunakan untuk menuliskan daftar pustaka secara otomatis, yakni Mendeley. Mendeley ini sangat mudah digunakan dan sifatnya online. Jadi, referensi yang kita input kedalam aplikasi ini akan di sinkronkan ke drive mendeley. Sudah pasti hal tersebut akan sangat mempermudah saat kita pindah komputer, tanpa harus mengcopy-paste referensinya secara manual.
\end{abstract}

Kata Kunci: Karya ilmiah, Tugas akhir, Referensi, Otomatis

\begin{abstract}
In writing scientific papers, whether thesis, thesis, or dissertation. Include bibliography is something that must be done to avoid plagiarism. In writing the final assignment, students cannot be separated from the reference name. There will be many references that we will paste in making the paper. It will certainly be difficult for us if we make a bibliography manually. Bibliography as much as possible included in complete and uniform, in accordance with the pattern or style recommended by the standard of scientific writing on the campus. To make it easier to create a bibliography automatically, there is now an application that we can use to write a bibliography automatically, namely Mendeley. Mendeley is very easy to use and online. So, references that we input into this application will be synchronized to the Mendeley drive. Certainly this will greatly facilitate when we move computers, without having to copy-paste the references manually.
\end{abstract}

Keywords: Scientific work, Final project, Reference, Automatic 


\section{PENDAHULUAN}

Selama proses menempuh pendidikan di perguruan tinggi, mahasiswa akan banyak disuguhkan berbagai jenis tugas, baik dalam bentuk karya tulis maupun karya ilmiah atau praktek lapangan. Menjelang tingkat akhir, mahasiswa pun semakin akrab dengan aktivitas membuat karya ilmiah seperti makalah, proposal, dan skripsi/tesis/disertasi. Setelah semua itu disusun, tentunya mahasiswa pun akan diminta untuk memaparkan hasil dari apa yang telah dibuatnya tersebut. Penggunaan instrumen digital untuk memperbarui literatur ilmiah pada zaman sekarang, lebih canggih dari sebelumnya, kebutuhan yang banyak menuntut kita untuk menjadi ahli bedah dalam karya ilmiah. Hal ini yang menyebabkan seringnya menyimpan file dalam memori berbagai perangkat tidak tertata dengan rapih, yang pada akhirnya akan menyulitkan kita dalam mengelolanya.(Russo et al., 2013)

Kendala yang sering muncul dalam pemaparan karya tulis maupun karya ilmiah adalah, kurang teliti dalam mencantumkan kutipan dan merasa kesulitan dalam pengelolaan sumber referensi. Apabila referensi yang dicantumkan miliki cukup banyak sumber, penulisan sitasi pun harus jelas sesuai apa yang ia kutip dari sumber aslinya. Hal ini masih dianggap membingungkan bagi kebanyakan mahasiswa dalam menyusun karya ilmiah sebagai tugas akhir mereka. Oleh karena itu, untuk menghindari hal-hal yang akan dapat menyulitkan mereka dalam menghadapi tugas akhir, perlu adanya pelatihan dalam penulisan karya ilmiah dengan bantuan apkilasi tambahan yang akan dapat mempermudah mereka untuk menyusun tugas akhir. Tentu saja dalam hal ini kita membutuhkan sebuah aplikasi yang popular dan mudah dipahami untuk mempermudah penggunaannya, yang memiliki fungsi sebagai manajemen sitasi atau manajemen referensi, karena penulis membutuhkan sistem yang terintegrasi untuk membantu mereka dalam meningkatkan produktivitasnya.(Zabidi, 2019)

Perkembangan teknologi informasi dalam dunia pendidikan sudah sangat pesat, sehingga mahasiswa harus mengenal berbagai aplikasi untuk mempermudah aktivitas mereka. Banyak penulis yang mengelola sebagian besar informasi bibliografi mereka secara elektronik, sehingga mengatur publikasi dan materi kutipan mereka dari perpustakaan digital. Namun, sebuah perpustakaan telah digambarkan sebagai "thought in cold storage," dan sayangnya banyak perpustakaan digital dapat beku, impersonal, terisolasi, dan tempat tidak bisa diakses.(Hull et al., 2008) Hal penting yang harus menjadi pertimbangan dalam memilih aplikasi yaitu sejauh mana 
sebuah aplikasi dapat meringankan tugas mereka, memudahkan, mempercepat, serta dapat kompatibel dengan aplikasi lain yang digunakan.

Mendeley merupakan salah satu aplikasi wajib buat para mahasiswa, khususnya bagi mereka yang sedang menulis artikel ilmiah, jurnal, ataupun skripsi.(Aji, 2016) Penggunaan aplikasi Mendeley akan sangat membantu mahasiswa dalam penyisipan, penulisan, dan pemformatan sitasi atau citation. Selain itu, aplikasi ini juga dapat juga digunakan untuk mengelola file artikel jurnal online yang merupakan output dari sebuah karya ilmiah.(Windarto et al., 2018) Dengan bantuan aplikasi ini, mahasiswa tidak akan lagi kesulitan dalam membuat sitasi. Sebagai mahasiswa, seharusnya sudah sangat familiar dengan aplikasi yang sangat membantu dalam penulisan karya tulis ilmiah. yang mana dalam proses tersebut kita sering kali dihadapkan dalam sebuah kendala. Kendala tersebut tidak selalu masalah substansi, tetapi masalah-masalah yang kadang kita anggap sepele namun amat penting. Misalnya format penulisan dan referensi ilmiah.(Riset et al., 2016)

Tujuan penulisan sumber sitasi dan daftar pustaka (reference or bibliography) adalah supaya kita terhindar dari penjiplakan (plagiarism). Salah satu fungsi kutipan adalah sebagai pendukung maupun penguat tulisan kita. Oleh karena itu, kita harus mencantumkan sumber kutipan tepat sebelum atau setelah kalimat sitasi yang ditulis secara singkat dan menuliskan sumber kutipan tersebut secara lengkap pada bagian daftar pustaka.(Azaria, 2016) Hal ini perlu dilakukan sebagai bentuk penghargaan dan pengakuan bahwa teks pada suatu bagian yang telah dikutip tersebut merupakan berasal dari ide, argumen, dan atau analisa penulis sebelumnya atau orang lain. Membantu para pembaca yang ingin mengetahui lebih dalam mengenai sumber kutipan, melalui daftar pustaka, pembaca dapat menelusuri informasi dari sumber kutipan dan mendapatkan rincian secara lengkap. (Gerakan Menulis Buku Indonesia, 2020)

Seperti yang sudah kita ketahui bahwa "Citation" merupakan elemen penting dalam sebuah penulisan karya ilmiah dan penggunaan software sitasi juga menjadi salah satu syarat agar naskah dapat terbit di jurnal.(Yusdita \& Utomo, 2019) Sitasi juga harus dilakukan dengan menggunakan gaya tertentu yang dikenal sebagai gaya sitasi (citation style).(Imam et al., 2019) Seringkali mahasiswa sebagai penyusun karya ilmiah terjebak dalam tindakan plagiasi yang tidak disengaja karena kurang hati-hati dalam membuat sebuah kutipan. Oleh sebab itu, keberadaan sebuah perangkat lunak yang berfungsi sebagai "citation \& reference manager" adalah sebuah kebutuhan. Dengan software tersebut, setiap penulis dapat mengidentifikasi kualitas dan keaslian dalam 
melacak setiap referensi yang digunakan. Di samping itu dengan "citation \& reference manager", penulis dapat mengolah sumber referensi yang dimiliki, membuat pengelompokan berdasarkan topik/kategori tertentu, sekaligus me-retrieve metadata yang terdapat di dalam dokumen. (Haxa Supriyanto, 2017)

Mendeley merupakan kombinasi dari aplikasi desktop dan situs web yang dapat digunakan untuk mengelola, berbagi, dan mencari referensi maupun kontak.(Sani M. Isa, 2005) Pengguna Mendeley perlu menyimpan semua data sitiran dasar di servernya. Setelah mendaftar, Pengguna dapat memanfaatkan ruang penyimpanan gratis di web sebesar 2 GB untuk menyimpan salinan dokumen pada server Mendeley.

Mendeley juga merupakan sebuah academic social network, dengan demikian pengguna dapat saling berbagi referensi yang digunakan dengan rekan mahasiswa ataupun peneliti lainnya di seluruh penjuru dunia. Selain itu, pengguna juga dapat mencari berbagai penelitian terbaru untuk dijadikan sebagai referensi dalam karya ilmiah. Bahkan, pengguna juga bisa menggunakan fasilitas Web Importer di dalam Mendeley, sehingga pengguna dapat menambahkan berbagai macam referensi dari berbagai situs indexing karya ilmiah terkemuka (misalnya Google Scholar) secara otomatis.(Fakultas Ekonomi dan Bisnis, 2020) Dengan demikian, pengguna dapat menggunakan Mendeley sebagai sebuah aplikasi desktop yang terinstal secara offline di komputer. Aplikasi tersebut, sering disebut sebagai Mendeley Desktop. Mendeley memungkinkan kita untuk melek terhadap informasi dengan tingkat yang lebih tinggi dan membantu penggunanya.(MacMillan Don, 2012) Selain itu, pengelolaan menggunakan Mendeley juga dapat dilakukan secara online (Mendeley Web), tentu saja semua itu dapat dilakukan setelah terlebih dahulu mendaftar dan membuat akun Mendeley.(Djamaris, 2017)

Pengaturan dan manajemen file hasil download sangat mudah dilakukan dengan "drag and drop", sehingga terasa sangat user friendly. Selain itu, perangkat lunak plug-in Microsoft Word yang memungkinkan penulisan sitasi maupun daftar pustaka secara otomatis berdasarkan database Mendeley. Pencarian teks lengkap untuk semua tulisan dalam database pribadi dan dapat disaring oleh penulis berdasarkan jurnal atau kata kunci.(Singh, 2010) Fungsi OCR (Optical Character Recognition) yang memungkinkan ektraksi detail dokumen secara otomatis terhadap paper hasil scan. Karena Mendeley merupakan perangkat lunak barbasis open source, maka perkembangan dari perangkat ini sangat pesat, hal ini ditandakan dengan penambahan fungsi- 
fungsi lain yang senantiasa ditambahkan oleh anggota komunitas untuk turut berperan aktif dalam meningkatkan kemampuan dari perangkat lunak tersebut.

\section{BAHAN DAN METODE}

Mendeley merupakan program komputer dan web yang dikembangkan oleh Elsevier dan berfungsi sebagai sarana pengelola dan berbagi makalah penelitian, mencari data penelitian, serta bekerja sama secara daring. (Jason Fitzpatrick, 2009) Mendeley Desktop merupakan aplikasi yang menggabungkan antara perangkat lunak manajemen referensi dan PDF. Mendeley juga dapat diartikan sebagai salah satu perangkat lunak pengelola referensi berbasis open source yang dapat diperoleh secara gratis serta mendukung berbagai platform seperti Microsoft Windows, Apple Mac OS, maupun Linux. Versi terbaru dari Mendeley bahkan sudah dapat digunakan pada sistem operasi Android, sehingga perangkat ini dapat dengan mudah digunakan pada ponsel. Beberapa fitur utama yang ada pada aplikasi Mendeley, antara lain (Haxa Supriyanto, 2017):

1. Ekstraksi detil dokumen (judul, penulis, nama jurnal, dll.) dari paper ke dalam database referensi. Fitur ini sangat berfungsi untuk memudahkan pengguna dalam memasukkan informasi detil dokumen karena hal tersebut dapat dilakukan secara otomatis tanpa perlu melakukan entri data secara manual. Semakin banyak pengguna yang menggunakan Mendeley, maka kualitas ekstraksi yang diperoleh pengguna akan semakin baik.

2. Pengelolaan referensi yang efisien dengan menyediakan "live" full-text search terhadap seluruh paper dalam database.(Hukum, 2020) Proses pencarian pada Mendeley sangat efisien karena hasil pencarian dapat langsung tersedia sesaat setelah pengguna selesai memasukkan kata kunci. Mendeley desktop juga menyediakan fungsi untuk melakukan filter database berdasarkan kata kunci, penulis, dan jurnal. Koleksi dokumen yang telah di unggah pada Mendeley dapat juga diberi catatan berupa notes atau tag sehingga pengguna dapat secara mudah melakukan pengorganisasian berdasarkan domain pengetahuan.(Digital Media IT, 2019) Informasi detil dari dokumen juga dapat diekspor ke berbagai citation styles.

3. Berbagi sebagian ataupun semua dokumen pada database dengan pengguna Mendeley lainnya sekaligus sinkronisasi pustaka referensi dengan data yang telah tersimpan pada server web Mendeley. Kemampuan ini akan sangat berguna bagi para pengguna Mendeley dalam sebuah riset maupun penulisan karya ilmiah yang dilakukan oleh sebuah tim, pustaka referensi dari seorang anggota tim akan selalu sinkron dengan anggota-anggota tim lainnya. 
4. Menampilkan metadata dari sebuah file PDF secara otomatis.

5. Backup dan sinkronisasi data dari beberapa komputer dengan akun online.

6. Smart filtering dan tagging.

7. PDF viewer dengan kemampuan anotasi dan highlighting.

8. Impor dokumen dan makalah penelitian dari situs-situs eksternal (misalnya PubMed, Google Scholar, arXiv, dll).

9. Integrasi dengan berbagai perangkat lunak pengolah kata seperti MS Word, Open Office, dan Libre Office.

10. Free web storage sebesar 2 GB yang dapat dimanfaatkan sebagai online backup.

Dalam setiap karya tulis atau karya ilmiah, pasti ada bagian yang biasanya diambil berdasarkan dari ide, argumen, analisa, dan atau hasil penelitian orang lain. Hal tersebut biasa kita sebut sebagai kutipan atau sitasi (citation). Sitasi atau kutipan (citation) adalah referensi untuk segala jenis dokumen (buku, artikel jurnal, disertasi, manuscript, koran, laporan, artikel dalam website, komposisi music, video dsb) yang secara jelas menunjukkan sumber sitasi tersebut sebagai informasi yang mengenali sumber yang kita gunakan dalam makalah akademis formal, dan memungkinkan pembaca menemukan sumber tersebut melalui informasi utama yang disajikan. (MIT Libraries, 2009), (Texas A\&M University Libraries, 2015) Kegunaan dari sitasi adalah yang kita gunakan adalah untuk mendukung argumen dan analisis karya tulis atau karya ilmiah yang kita susun. Sitasi bisa diambil dari berbagai sumber, baik buku teks maupun audio visual, baik dari media print sampai online, juga bisa dokumen yang bersifat published maupun unpublished. Semua jenis dokumen dapat kita gunakan untuk menjadi bagian dalam tulisan atau karya tulis yang kita susun sebagai bukti pendukung, yang perlu diingat adalah setiap kali kita mengambil ide, argumen, tulisan, hasil penelitian dari orang lain, kita harus mencantumkan asalusul dari kutipan yang kita ambil secara mendetail kedalam catatan dan daftar pustaka.

Berdasarkan hal tersebut, penulis memberikan pelatihan khusus terhadap mahasiswa STIKes Cirebon, khususnya yang berada pada tingkat akhir agar mereka memahami fungsi dan penggunaan aplikasi ini dengan tujuan agar mereka dapat menyusun tugas akhir mereka dengan baik dan benar sesuai pedoman penulisan karya ilmiah serta menghindari plagiarisme. Diharapkan setelah pelatihan ini, mahasiswa dapat secara mandiri menerapkan aplikasi mendeley dengan baik pada karya tulis mereka masing-masing sehingga mendapatkan hasil yang memuaskan. 


\section{HASIL DAN PEMBAHASAN}

\section{Install Aplikasi Mendeley Desktop}

Sebelum kita mulai menggunakan aplikasi Mendeley untuk membuat refrensi dan daftar pustaka secara otomatis pada karya ilmiah baik itu berupa Skripsi, tesis disertasi, buku, journal, maupun karya ilmiah lainnya, langkah awal yang harus kita lakukan adalah menginstal aplikasi Mendeley Desktop terlebih dahulu di komputer atau laptop. Pada tutorial ini kita akan bersamasama menginstall aplikasi Mendeley dengan versi: Mendeley-Desktop-1.19.4-win32. Untuk lebih jelasnya, mari bersama-sama kita ikuti langkah-langkah sebagai berikut:

1. Download terlebih dahulu aplikasinya di alamat: https://www.mendeley.com/downloaddesktop-new/\#download, lalu klik menu Download Mendeley Desktop for Windows. Maka akan tampil seperti berikut :

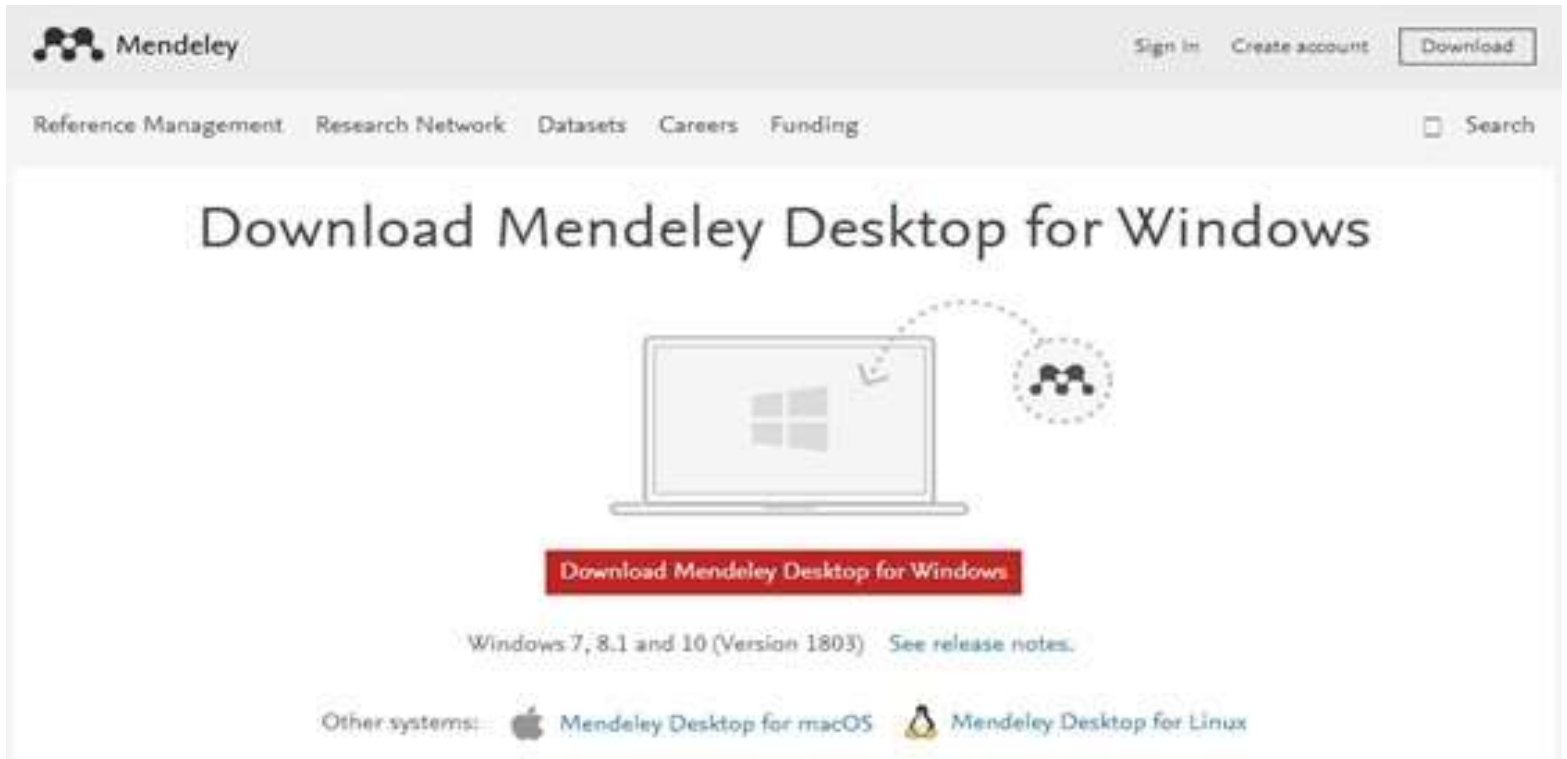

2. Setelah selesai download aplikasi tersebut, lihat lokasi penyimpanan dimana direktori tersebut didownload:

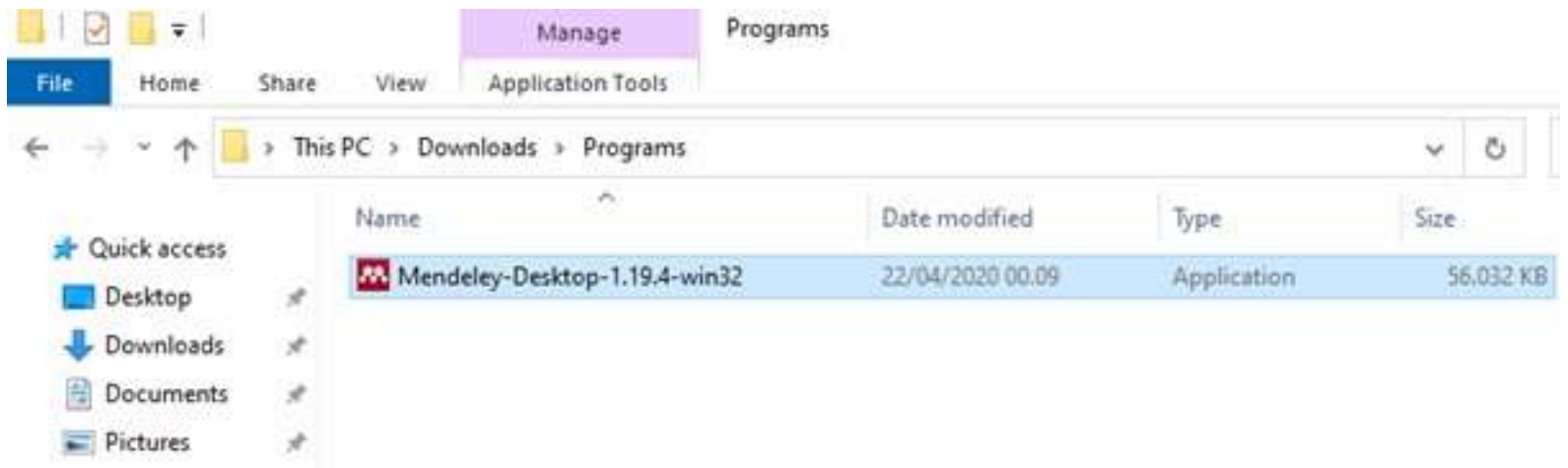


3. Double Klik aplikasi Mendeley-Desktop-1.19.4-win32 tersebut untuk memulai menginstal pada komputer kita:

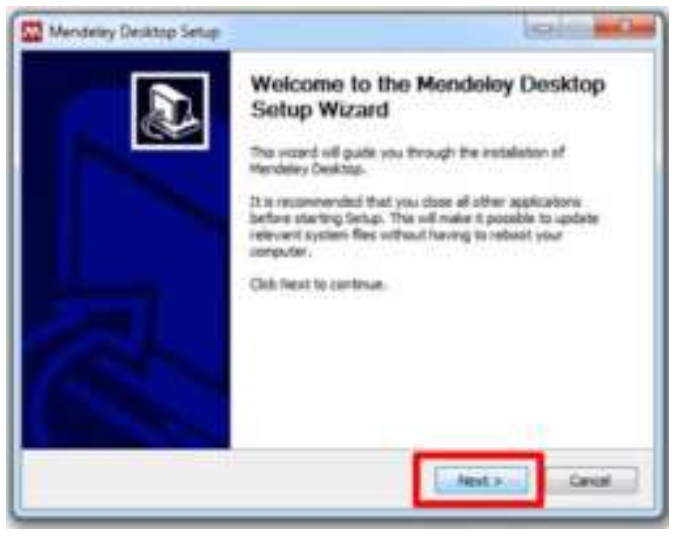

Klik Next untuk melanjutkannya ketahap berikutnya.

4. Setelah klik Next akan muncul tampilan seperti dibawah ini:

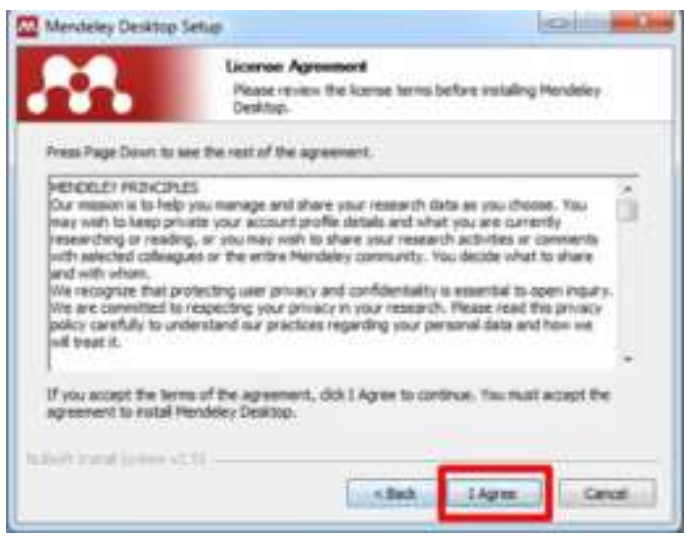

Klik I Agree untuk menyetujui dan melanjutkan penginstalan

5. Stelah kita klik I Agree, berarti kita menyetujui dan melanjutkan proses penginstallan seperti dibawah ini:

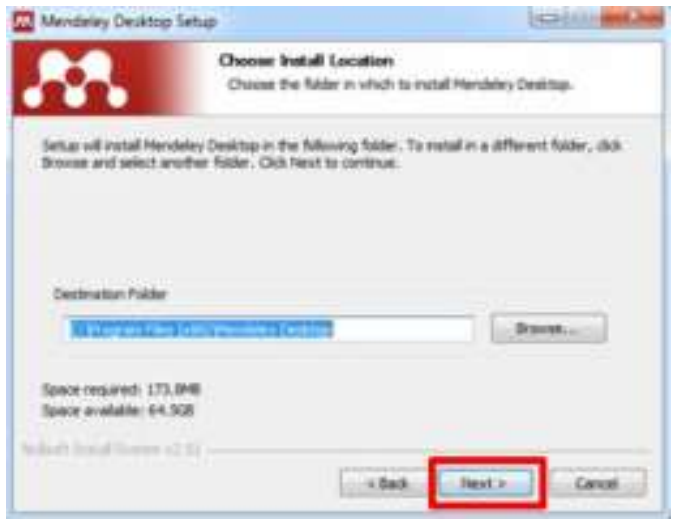

Klik Next untuk melanjutkan installasi 
6. Aplikasi akan menuju proses installasi dan kita tunggu beberapa saat sampai muncul tampilan berikut :

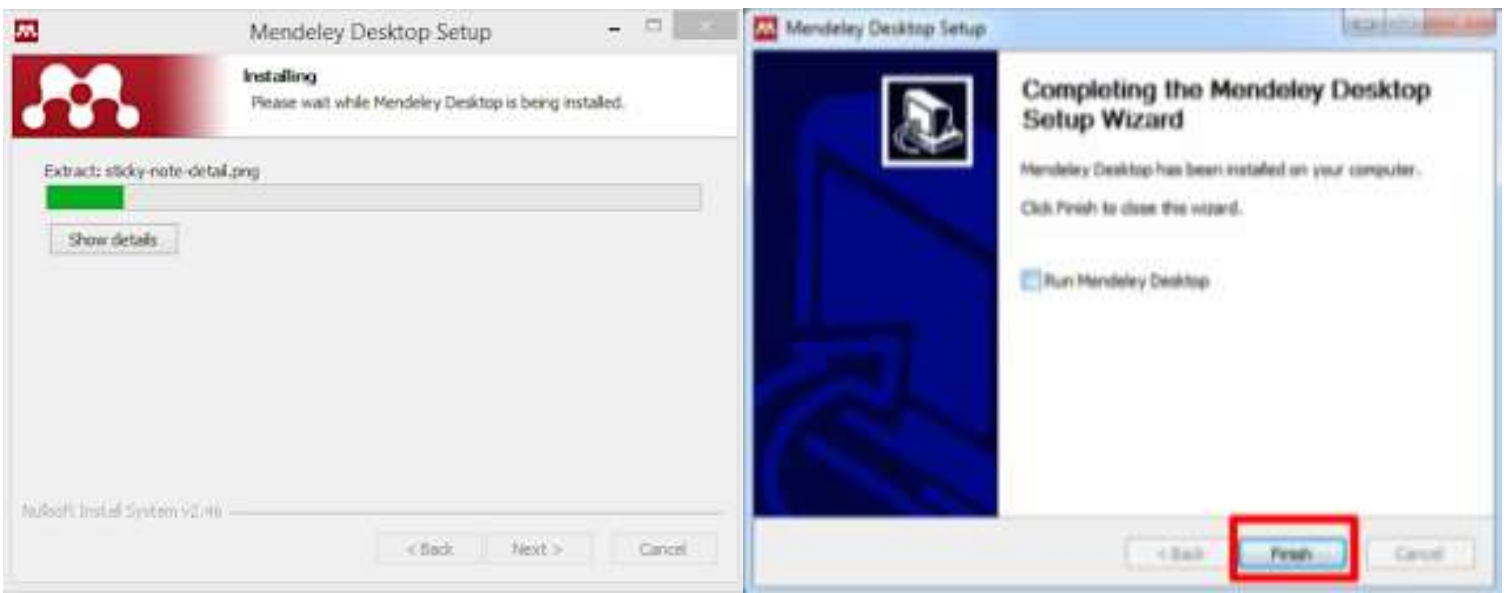

Finish, yang artinya kita sudah selesai menginstall aplikasi Mendeley Dekstop.

7. Ketika muncul tampilan Welcome to Mendeley, itu menandakan bahwa aplikasi Mendeley Desktop sudah siap digunakan.

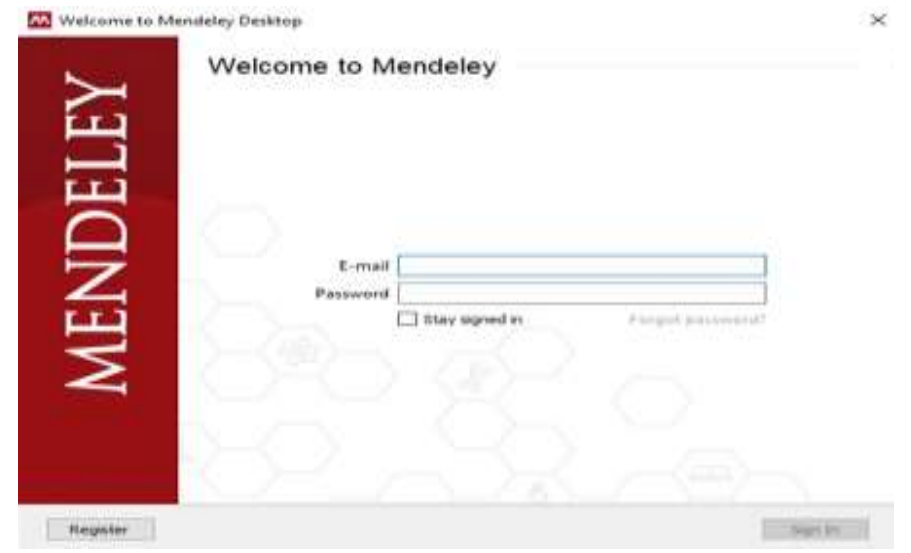

Dengan mengikuti tutorial diatas sampai selesai, kita sudah sukses menginstall aplikasi Mendeley Desktop pada computer atau laptop kita, dan aplikasi Mendeley pun siap untuk digunakan. Langkah selanjutnya yang akan kita lakukan adalah membuat akun bagi yang belum memiliki akun, atau Sign In bagi yang sudah memiliki akun.

\section{Membuat Akun Mendeley}

Langkah selanjutnya setelah kita selesai menginstall aplikasi Mendeley, kita harus terlebih dahulu membuat akun dengan email kita. Dalam membuat akun, hanya perlu membuat satu akun walaupun kita menggunakan banyak perangkat. Bagi pengguna aplikasi Mendeley, disarankan menggunakan akun email utama yang kita gunakan sebagai email default di internet browser di 
PC/Laptop, Hand Phone, atau perangkat lainnya. Hal ini ditujukan untuk sinkronisasi web importer maupun penggunaan Mendeley di Handpone/Tab. Adapun langkah- langkah registrasi Mendeley adalah sebagai berikut:

1. Buka halaman : https://www.mendeley.com/lalu Klik Create account

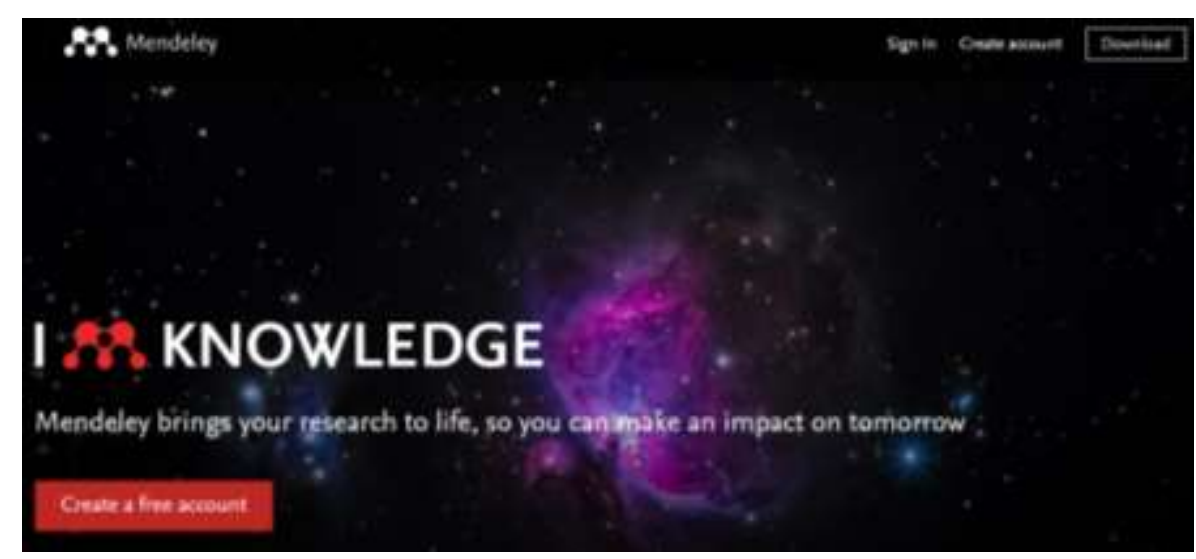

2. Masukan email kita, lalu klik Continue untuk memulai Mendeley

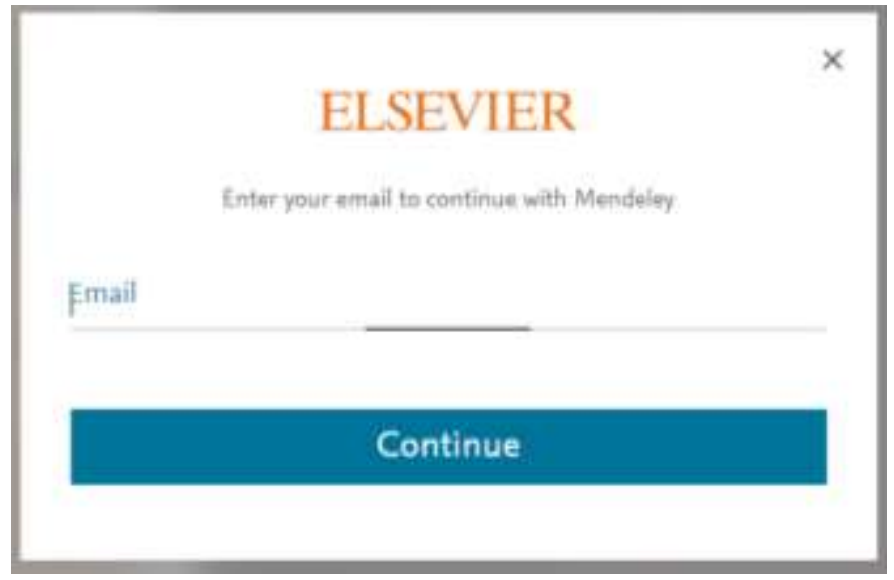

3. Lengkapi Given name, Family name dan Password, lalu klik Register. Setelah selesai Register, maka akan muncul tampilan Registration successful seperti dibawah ini: 


\section{ELSEVIER}

Register

Create password to register

\begin{tabular}{l} 
Email \\
panduanapllikasimendeley@gmail.com \\
Given name \\
Tutorial \\
Family rame \\
Mendeley \\
Password \\
......... \\
Bu Stay signed in (not recommended for shared devices) \\
By continuing you agree with our Terms and conditions and Privacy \\
policy. \\
Register \\
\hline I already have an account
\end{tabular}

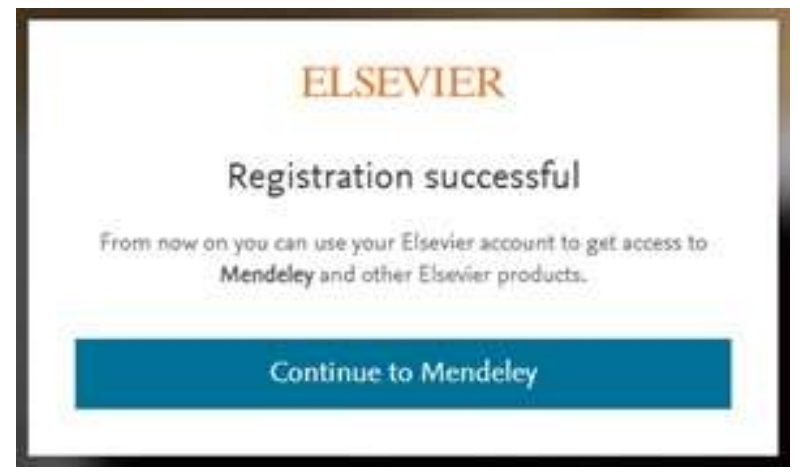

4. Lengkapi Current role (peran kita saat ini) dan Field of study (bidang studi)

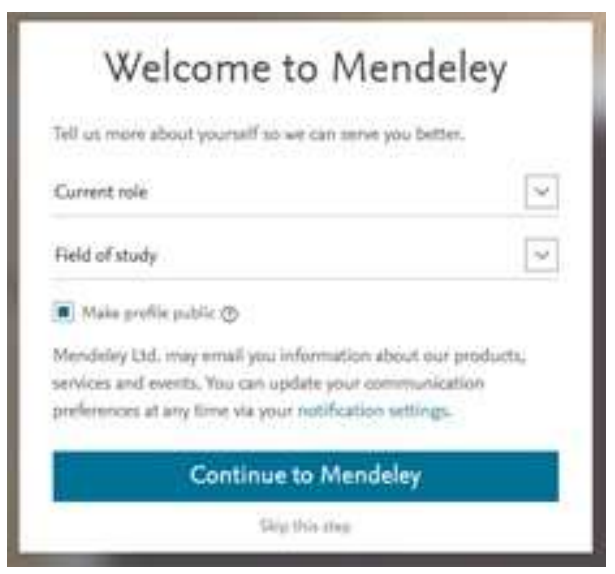

5. Berikut adalah tampilan ketika selesai membuat akun Mendeley:

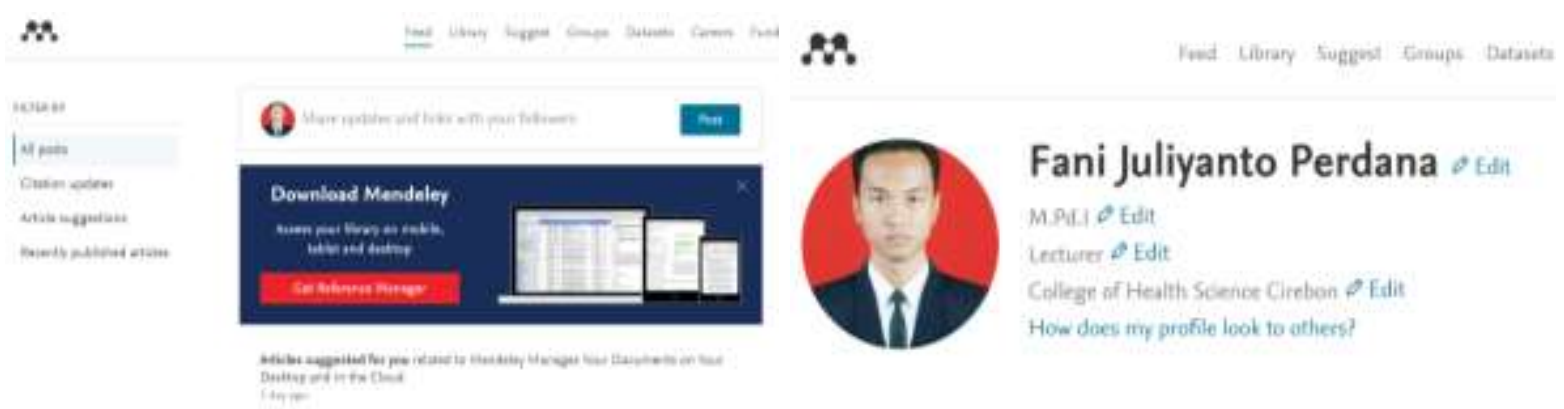

Setelah selesai registrasi, kita akan memiliki akun Mendeley di web dan akun tersebut akan sinkron dengan akun yang kita miliki di Mendeley Desktop. Setelah mempunyai akun Mendeley 
kita dapat login dengan memasukkan email dan password yang benar sesuai dengan yang kita buat saat register.

\section{Integrasi Mendeley dengan Microsoft Word}

Kemudahan dalam menggunakan aplikasi Mendeley desktop salah satunya yaitu dapat berkolaborasi dengan Microsoft Office (Word) dalam penyusunan sitasi dan daftar pustaka sehingga akan mempermudah pembuatan daftar referensi karya ilmiah, karena dalam satu kali klik maka seluruh referensi telah tersusun sesuai dengan keinginan penulis.

1. Setelah berhasil login, mendeley akan menyodorkan layar yang menampilkan pilihan untuk install Plugin mendeley di Microsoft Word, klik Install Now.

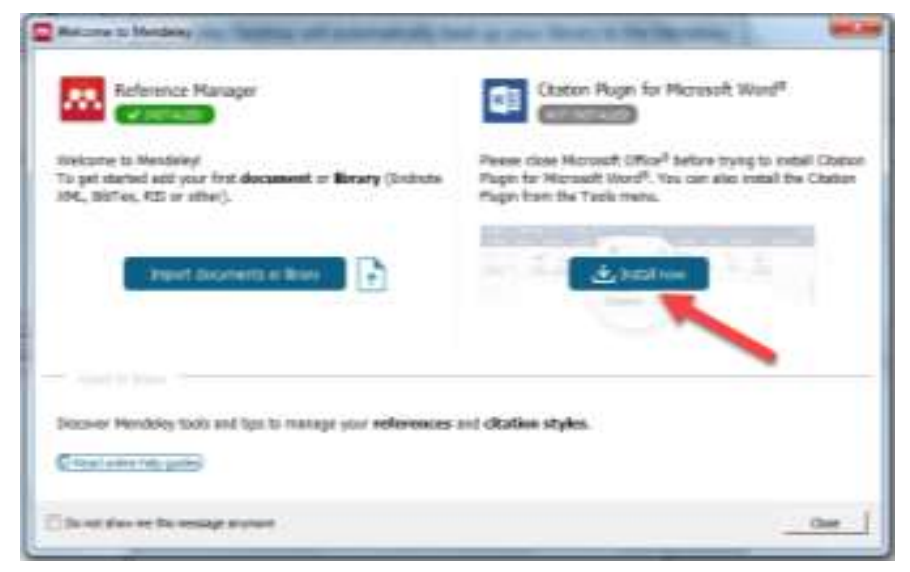

2. Selain cara tersebut, dapat juga dilakukan pada tampilan setelah login di aplikasi Mendeley Desktop, dengan klik Tools, lalu Install MS Word Plugin.

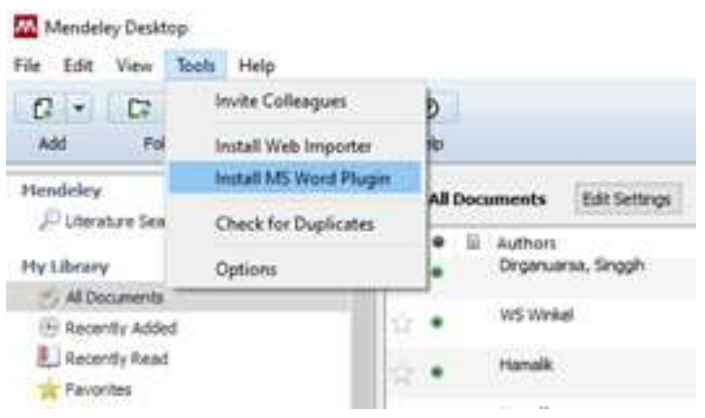

3. Jika install plugin sukses, status,nya akan terlihat seperti gambar di bawah ini:

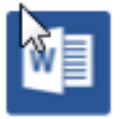

\section{Citation Plugin for Microsoft Word ${ }^{\circledR}$}

\section{$\checkmark$ INSTALLED}

4. Perbedaan tampilan sebelum dan sesudah Install MS Word Plugin. 
Sebelum:

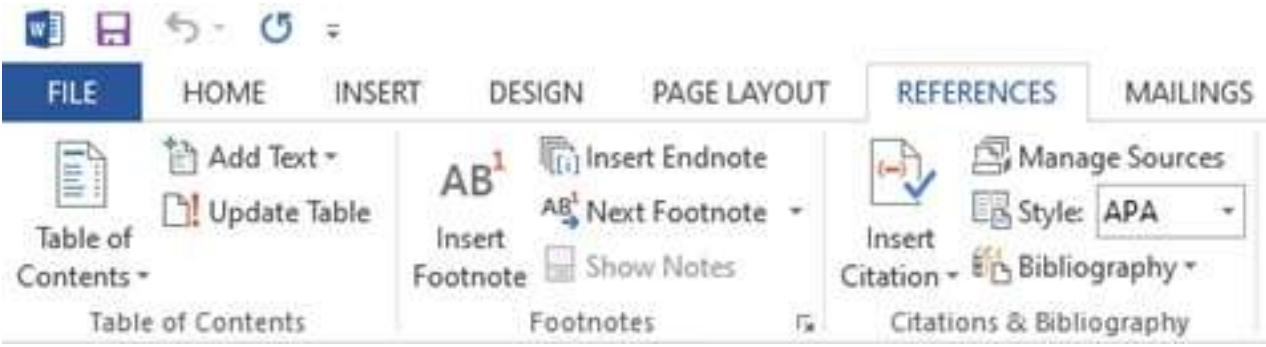

Sesudah:

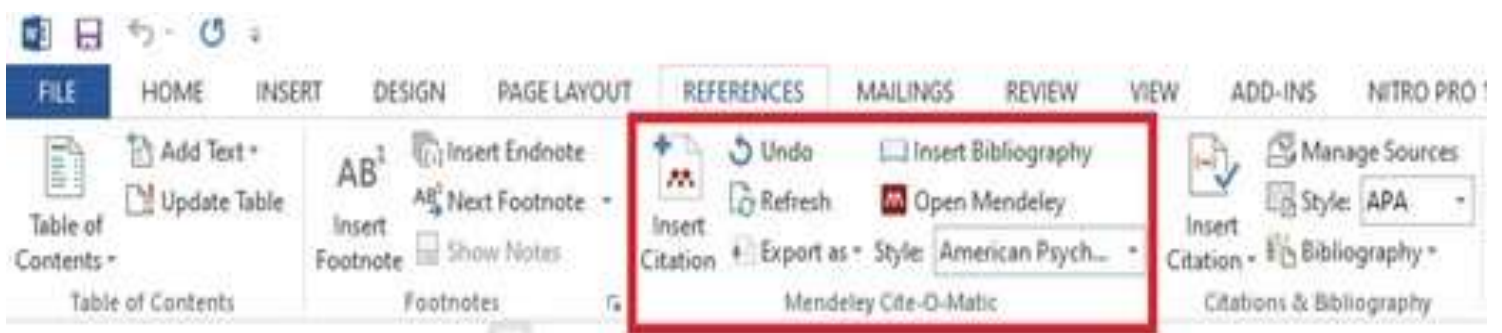

\section{Memasukkan Referensi Pada Aplikasi Mendeley}

Menambahkan referensi pada aplikasi Mendeley bias dilakukan dengan beberapa jenis, yaitu dapat menambahkan referensi berupa file PDF yang mana akan lebih mempermudah dalam penelusuran kalimat atau sumber bacaan yang kita kutip kedalam tulisan kita, atau menambahkan secara manual dari sumber referensi tertentu yang mana hanya akan menampilkan sumber referensi saja yang akan disisipkan pada Daftar Pustaka. Untuk menambah referensi pada aplikasi Mendeley kita dapat mengikuti langkah-langkah berikut:

1. Klik Add :

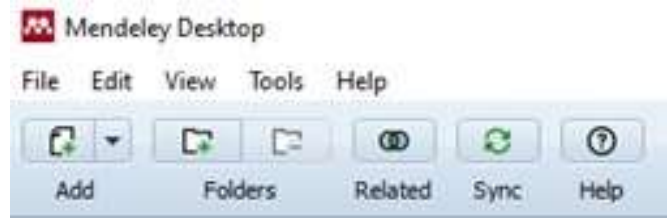

2. Pilih :

$$
\begin{aligned}
& \text { Add Files } \\
& \text { Add Folder } \\
& \text { Watch Folder } \\
& \text { Add Entry Manually }
\end{aligned}
$$

Add Files (jika ingin menambahkan file berupa PDF)

Add Entry Manually (jika ingin menambahkan referensi secara manual) 
3. Pada New Document, pilih tipe referensi, pada contoh ini kita pilih "Book" untuk memasukkan referensi berupa buku, lalu lengkapi informasi yang dibutuhkan seperti ini:

\begin{tabular}{|l|}
\hline Nype: Book \\
Tutorial Mendeley \\
Authors: Juliyanto \\
Year: 2020 \\
\hline Pages: \\
Abstract: \\
Tags: \\
Author Keywords: \\
\hline City: \\
\hline Cirebon \\
\hline Edition: \\
\hline Editors: \\
\hline Publisher: \\
\hline Nurjati Press \\
\hline Reset \\
\hline
\end{tabular}

Klik Save untuk menyimpan informasi referensi.

4. Mendeley akan menampilkan detil referensi sebagai berikut:

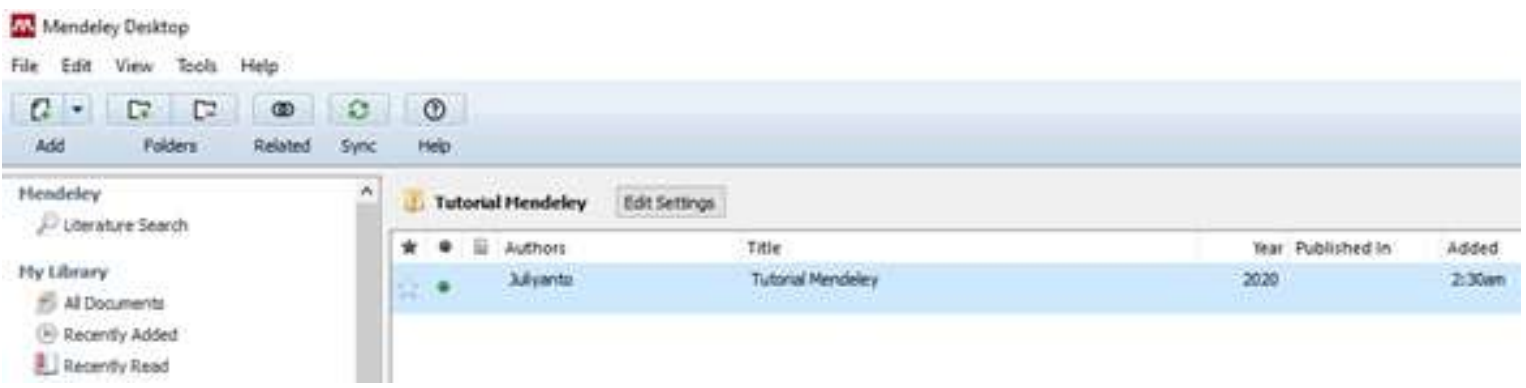

\section{Mengutip Sitasi atau kutipan dengan Aplikasi Mendeley di Microsoft Word}

Mengutip referensi pada sebuah karya ilmiah tentu merupakan hal yang sangat penting. Bahkan beberapa lembaga memiliki standar atau aturan yang mengatur cara pengutipan dan juga pembuatan daftar pustaka. Misalnya dalam membuat proposal penelitian, skripsi, tesis, disertasi atau artikel ilmiah yang akan diterbitkan pada jurnal ilmiah. Untuk dapat mengutip referensi dan membuat daftar pustaka yang baik dapat dilakukan dengan aplikasi Mendeley. Berikut ini adalah langkah-langkah untuk mengutip referensi pada Microsoft Word dengan aplikasi Mendeley: 
1. Posisikan kursor pada teks yang akan dicantumkan Sitasi atau kutipan.

\section{PELATIHAN MEMBUAT DAFTAR PUSTAKA OTOMATIS DENGAN APLIKASI MENDELEY DESKTOP BAGI MAHASISWA DALAM PERSIAPAN PENYUSUNAN TUGAS AKHIR}

Dalam penulisan karya ilmiah, baik skripsi, thesis, maupun disertasi. Mencantumkan daftar pustaka adalah hal yang wajib dilakukan untuk menghindari plagiarism. Dalam melakukan penulisan tugas akhir mahasiswa tidak lepas dari yang namanya referensi. $\mid$

2. Klik Pada Tab References, lalu klik Insert Citation.

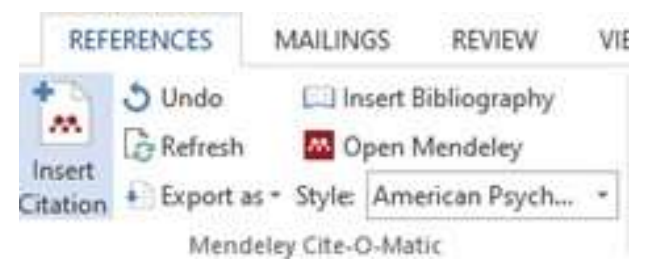

3. Setelah klik Insert Citation, akan muncul seperti dibawah ini:

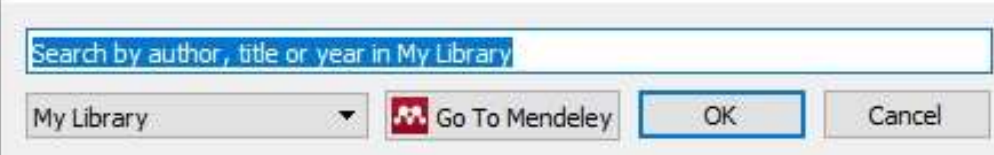

4. Ketik kata kunci (keyword), maka referensi yang dimaksud akan muncul, lalu kita pilih dengan klik OK.

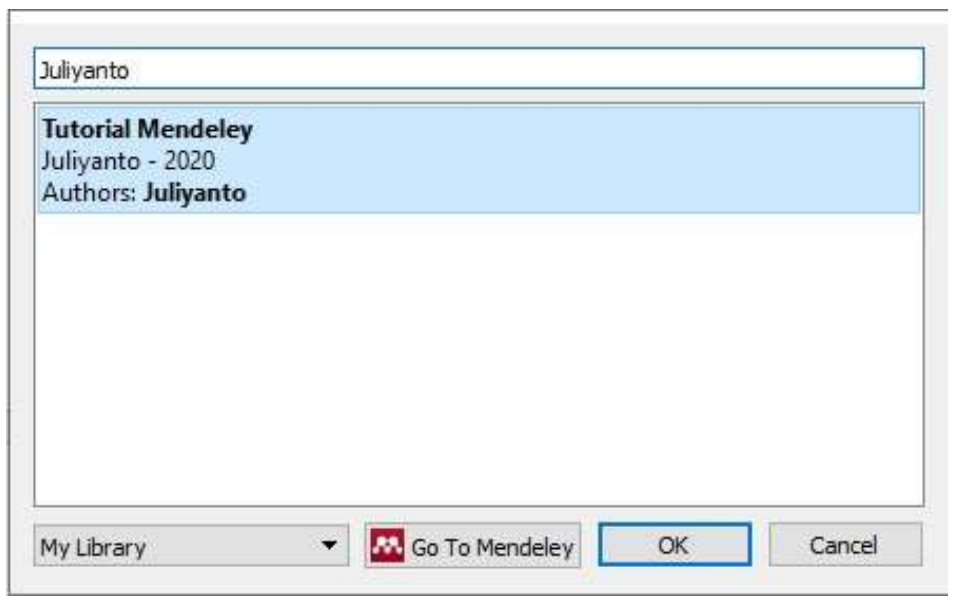

5. Setelah disisipkan, maka tampilan pada dokumen menjadi seperti gambar berikut ini:

\section{PELATIHAN MEMBUAT DAFTAR PUSTAKA OTOMATIS DENGAN APLIKASI MENDELEY DESKTOP BAGI MAHASISWA DALAM PERSIAPAN PENYUSUNAN TUGAS AKHIR}

Dalam penulisan karya ilmiah, baik skripsi, thesis, maupun disertasi. Mencantumkan daftar pustaka adalah hal yang wajib dilakukan untuk menghindari plagiarism. Dalam melakukan penulisan tugas akhir mahasiswa tidak lepas dari yang namanya referensi. (Juliyanto, 2020) 
6. Sitasi atau kutipan akan secara otomatis muncul berdasarkan "Style" referensi yang dipilih. Jika menginginkan merubah style silahkan pilih style seperti pada gambar berikut:

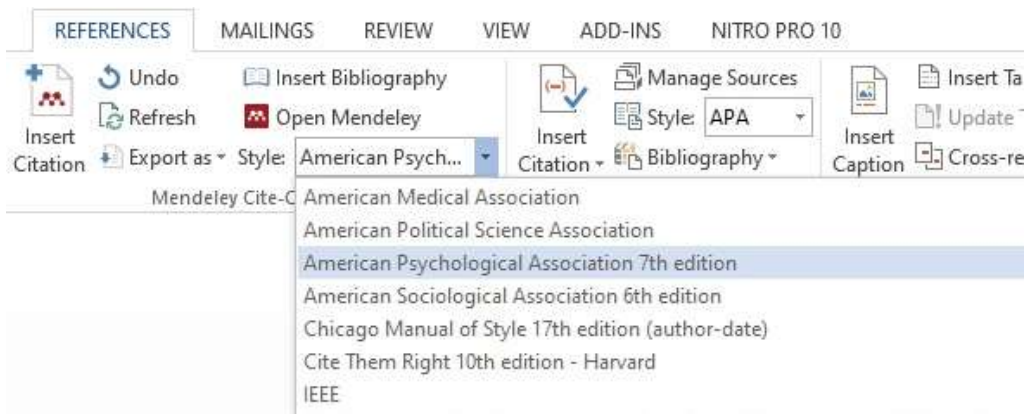

\section{Memasukan Daftar Pustaka Secara Otomatis dengan Mendeley}

Setelah sitasi atau kutipan kita sisipkan pada kalimat yang kita ambil dari sebuah sumber, selanjutnya kita akan membuat Daftar Pustaka secara otomatis berdasarkan kutipan yang kita ambil dari sumber-sumber referensi. Langkah untuk membuat daftar pustaka secara otomatis di Microsoft Word dengan Mendeley sangatlah mudah, yakni kita hanya cukup klik Insert Bibliography pada Tab References, maka kumpulan sumber referensi yang kita kutip akan muncul semua dalam Daftar Pustaka.

1. klik References, lalu klik Insert Bibliography pada Plugin Mendeley.

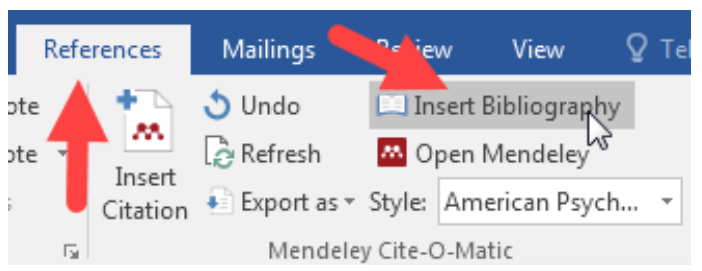

2. Daftar Pustaka yang akan muncul setelah klik Insert Bibliography pada Plugin Mendeley.

DAFTAR PUSTAKA

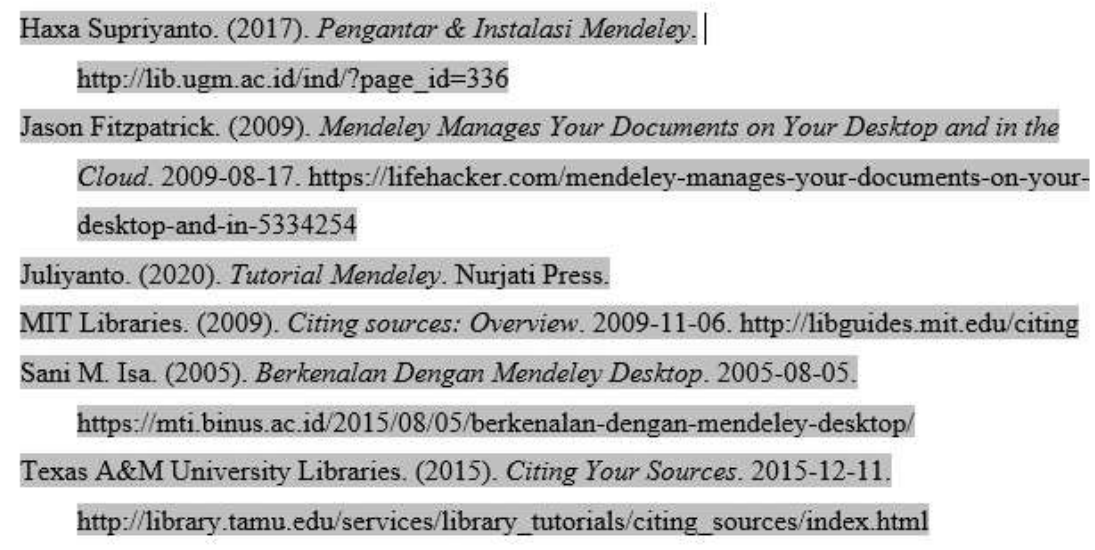




\section{KESIMPULAN DAN SARAN}

Dari pembahasan di atas, penulis dapat menyimpulkan bahwa banyak manfaat dari pelatihan aplikasi Mendeley yang diberikan kepada mahasiswa. Salah satunya akan dapat meningkatkan pengetahuan sekaligus sebagai stimulant agar para mahasiswa lebih kreatif dalam membuat referensi karya ilmiah yang interaktif. Pelatihan yang diberikan merupakan sebuah kegiatan yang bertujuan membantu mahasiswa dalam mengelola referensi dengan baik untuk meningkatkan kualitas pendidikan di Indonesia. Pada prosesnya mahasiswa cenderung masih banyak yang menggunakan metode konvensional ketika menulis karya ilmiah khususnya pada bagian pengutipan. Tujuan dari pelatihan ini salah satunya dengan harapan mahasiswa sudah dapat mensitasi dan membuat daftar pustaka otomatis dengan menggunakan aplikasi Mendeley di karya ilmiah masing-masing. Membantu mahasiswa dalam memudahkan mereka menulis karya ilmiah merupakan tanggung jawab kita bersama selaku pihak lembaga. Oleh karena itu, pelatihan semacam ini sangat diperlukan. Dengan menyampaikan materi tentang penulisan karya ilmiah dan penggunaan Mendeley, para peserta menjadi terbantu yang tentu saja akan mendorong mereka untuk lebih produktif menghasilkan karya ilmiah.

\section{UCAPAN TERIMA KASIH}

Alhamdulillah, berkat kesempatan dan dukungan dari pihak-pihak yang terkait dengan pelaksanan pelatihan membuat daftar pustaka secara otomatis dengan menggunakan aplikasi Mendeley Desktop. Akhirnya tilisan ini dapat disusun sebagai tutorial bagi mahasiswa yang ingin mempelajari bagaimana menggunakan aplikasi mendeley secara mendasar. Akhir kata, saya ucapkan terimakasih kepada mahasiswa STIKes Cirebon, yang telah bersedia dan meluangkan waktunya untuk mengikuti pelatihan ini dengan baik.

\section{DAFTAR PUSTAKA}

Aji. (2016). Mendeley, Aplikasi Wajib Bagi Kamu Para Mahasiswa. 08/05/2016. https://macpoin.com/13873/mendeley-aplikasi-wajib-bagi-kamu-para-mahasiswa/

Azaria, S. (2016). Penulisan Sumber Kutipan dan Daftar Pustaka. Departemen Mata Kuliah Umum Universitas Kristen Petra.

Digital Media IT. (2019). Mendeley \& Word Reference Tools. 06/11/2019. https://fitritasari. wordpress.com/2019/11/06/pertemuan-ke-4-mendeley-word-reference-tools-untuk- 
mahasiswa-angkatan-2017-2018/

Djamaris, A. R. A. (2017). Panduan Penggunaan Mendeley (Versi 1.17.10). Journal of Entrepreneurship, Management and Industry (JEMI), 32. http://repository.bakrie.ac.id/ 1227/1/panduan mendeley.pdf

Fakultas Ekonomi dan Bisnis. (2020). Pengeloaan Referensi dan Sitasi dengan software Mendeley. Jurnal Ekonomi Manajemen, 164(24). https://feb.unsil.ac.id

Gerakan Menulis Buku Indonesia. (2020). Daftar Pustaka: Tata Cara Penulisan. 20/02/2020. https://gmb-indonesia.com/2019/02/20/penulisan-daftar-pustaka/

Haxa Supriyanto. (2017). Pengantar \& Instalasi Mendeley. http://lib.ugm.ac.id/ind/?page_id=336

Hukum, F. S. dan. (2020). Tingkatkan Keahlian Leteratur Review, Dosen Fsh Adakan Pelatihan Aplikasi Mendeley. 07/02/2020. https://mti.binus.ac.id/2015/08/05/berkenalan-denganmendeley-desktop/

Hull, D., Pettifer, S. R., \& Kell, D. B. (2008). Defrosting the digital library: Bibliographic tools for the next generation web. PLoS Computational Biology, 4(10). https://doi.org/10.1371/ journal.pcbi.1000204

Imam, M., Astuty, S., Samsir, A., Basra, A., \& Albi, M. F. (2019). Pelatihan penggunaan aplikasi Mendeley bagi mahasiswa Sekolah Tinggi Ilmu Pembangunan Indonesia ( STIE-PI ) Makassar dalam penulisan karya ilmiah. 414-417.

Jason Fitzpatrick. (2009). Mendeley Manages Your Documents on Your Desktop and in the Cloud. 2009-08-17. https://lifehacker.com/mendeley-manages-your-documents-on-your-desktopand-in-5334254

MacMillan Don. (2012). Mendeley: teaching scholarly communication and collaboration through social networking. Library Management, 33(8), 561-569.

MIT Libraries. (2009). Citing sources: Overview. 2009-11-06. http://libguides.mit.edu/citing

Riset, K., Dan, T., \& Tinggi, P. (2016). Modul Teknis Penggunaan Mendeley dalam Penulisan KTI. 5-8.

Russo, G. Lo, Spolveri, F., Ciancio, F., \& Mori, A. (2013). Mendeley: An Easy Way to Manage, Share, and Synchronize Papers and Citations. Plastic and Reconstructive Surgery, 131(6), 946-947. https://doi.org/10.1097/PRS.0b013e31828bd93a

Sani M. Isa. (2005). Berkenalan Dengan Mendeley Desktop. 2005-08-05. https://mti.binus.ac.id/ 2015/08/05/berkenalan-dengan-mendeley-desktop/ 
Singh, J. (2010). Mendeley: A free research management tool for desktop and web. Journal of Pharmacology \& Pharmacotherapeutics, 1(1), 62-63. https://doi.org/10.4103/0976$500 \times .64539$

Texas A\&M University Libraries. (2015). Citing Your Sources. 2015-12-11. http://library.tamu.edu/services/library_tutorials/citing_sources/index.html

Windarto, A. P., Hartama, D., Wanto, A., \& Parlina, I. (2018). Pelatihan Pemanfaatan Mendeley Desktop Sebagai Program Istimewa Untuk Akademisi Dalam Membuat Citasi Karya Ilmiah. AKSIOLOGIYA: Jurnal Pengabdian Kepada Masyarakat, 2(2), 145. https://doi.org/10.30651/aks.v2i2.1319

Yusdita, E. E., \& Utomo, S. W. (2019). Pelatihan Pemanfaatan Mendeley Sebagai Reference Tool Pada Artikel Ilmiah Mahasiswa Pendidikan Akuntansi Unipma. Jurnal ABDINUS : Jurnal Pengabdian Nusantara, 3(1), 36. https://doi.org/10.29407/ja.v3i1.13525

Zabidi, T. (2019). Analytical Review of Contemporary Fatwas in Resolving Biomedical Issues Over Gender Ambiguity. Journal of Religion and Health, 58(1), 153-167. https://doi.org/10.1007/s10943-018-0616-0 